\title{
Representações sociais de professoras sobre o prazer e desprazer nos seus trabalhos
}

\author{
Ivany Pinto Nascimento \\ Universidade Federal do Pará - Brasil
}

\begin{abstract}
Resumo
Este estudo investigou as Representações Sociais de professores de séries iniciais sobre o envolvimento da afetividade na sua profissão na perspectiva do prazer e desprazer. A Teoria das Representações Sociais serviu de referência para caracterizar e destacar os aspectos prazerosos e desprazerosos que se vinculam ao envolvimento afetivo. O instrumento de coleta de dados foi a escrita individual de um texto sobre os prazeres e os desprazeres da profissão docente. Sujeitos do estudo foram trinta e cinco professores. Os resultados indicam que os vínculos afetivos se representam no exercício da profissão muito mais pelo desprazer do que pelo prazer. Palavras chave: professoras, afetividade, representações, profissão.
\end{abstract}

Abstract
This study investigated the social representations of
teachers of initial series about the involvement of
affection in their profession from the perspective of
pleasure and displeasure. The theory of social
representations was the reference to feature and highlight
the pleasurable aspects and displeasure that link to
relationships. The data collection instrument was the
writing of a text about the pleasures and the displeasures
of the teaching profession. Study subjects were thirty-five
teachers. The results indicate that the affective links are
represented in the exercise of the profession much more
by displeasure than for pleasure.
Key words: teachers, affectivity, representations,
profession.

Este artigo visa apresentar os resultados parciais da pesquisa desenvolvida sobre as Representações Sociais de Professores de séries iniciais sobre o prazer e desprazer na sua profissão. Antes de explicitarmos a análise propriamente dita, discorreremos no tópico a seguir sobre alguns posicionamentos teóricos adotados.

Os estudos sobre o prazer e desprazer no trabalho em função de seus avanços, sobretudo no campo da psicologia possibilitaram compreender as condições nas quais o trabalho é uma fonte de prazer e, portanto se torna benéfico ao trabalhador e aquelas condições nas quais o trabalho é fonte de desprazer, e que por sua vez se torna um fardo pesado gerador de sofrimento e adoecimento.

A dialética prazer/desprazer no trabalho docente nos remete ao contexto histórico da profissão docente que, por sua vez se encontra vinculada a sua valorização social. Vale destacar que partimos do principio de que em toda relação existe prazer e desprazer, mas o que enfatizamos é que existem relações nas quais o desprazer é sempre muito mais acentuado do que o prazer. Isso gera desequilíbrio permanente responsável pelo sofrimento, desmotivação e mal estar permanente do sujeito. Desse modo, o trabalho bem como seu desenvolvimento e crescimento fica comprometido.

Pesquisadores como Oliveira e Freitas (2008) rememoram o surgimento da profissão docente ao dizer que ela surgiu sob a tutela da Igreja e a posteriori o Estado com o advento da República assumiu a responsabilidade. Desse modo, a representação da docência como sacerdócio, lugar de humildade, benevolência e obediência foi construída pela forte influência religiosa que perpassou e dominou a história da educação. Com o controle do Estado sobre a Educação esse imaginário persistiu e persiste até a contemporaneidade muito embora, sendo desconstruído pelos estudos que comprovam a manutenção dessa representação como forma de submetimento aos ditames das políticas educacionais.

Ao considerarmos que "a qualidade do ensino e a satisfação do professor no trabalho estão intimamente ligadas e que é improvável melhorar a qualidade do ensino sem primeiro entender quais as expectativas, motivos e interesses que ainda sustentam os professores em uma profissão em constante desvalorização" (MOREIRA, 1996, p.2).

Dentre as causas do desprazer no trabalho do professor podemos citar: falta de tempo para realizar um trabalho de qualidade; ausência da família na vida escolar dos alunos; falta de atualização para enfrentar as demandas que a sociedade impõe a profissão docente; desvalorização da profíssão (ESTEVE, 1987; GOMES, 1993; MARTÍNEZ e KOHEM, 1997) As pesquisas sobre prazer e desprazer no trabalho docente (GOMES e PEREIRA, 2009; MANCEBO, 2007), destacam que um dos sentidos do trabalho docente é o prazer. Freitas (2007) assinala alguns aspectos que o prazer expresso pela alegria na realização do trabalho docente se vincula: a liberdade de expressão; o dialogo com o conhecimento que leve ao crescimento interior e as aprendizagens importantes; á interação entre os colegas de trabalho; o reconhecimento e a valorização de seu trabalho e no grau de liberdade para planejar, controlar o tempo e o conteúdo a ser ministrado.

Uma das singularidades do trabalho docente é a construção do vínculo afetivo, sobretudo no ensino fundamental. Esse vínculo é fundante para a realização do trabalho docente, e pode ser prejudicado em função do desprazer do professor com o trabalho que desenvolve. Desse modo, o afeto além de representar a argamassa para o ensino-aprendizagem é mediador da relação entre o professor e o aluno. $\mathrm{O}$ prazer de ensinar é recebido pelo aluno como positivo e motivador para que ele aprenda e tenha prazer nesse processo. Se o 
desprazer é maior do que o prazer para o professor ele também transmite para o seu aluno, que por sua vez sente desprazer não somente na relação com o professor como também na situação de aprendizagem. Se o afeto investido pelo professor no seu trabalho não tiver um retorno prazeroso necessário para que ele possa enfrentar as adversidades que por ventura surgirem no processo ensino-aprendizagem esse afeto se dissipa.

Os estudos que versam sobre o trabalho destacam que os caminhos para lidar com o desprazer devem partir de uma construção coletiva. Para tanto, a psicodinâmica que mantém o desprazer no caso do trabalho do professor deve ser ressignificada no sentido de reorganização em prol do prazer que advém de um ambiente mais humanizado onde os professores e demais componentes que integram o corpo escolar se encontram abertos para o diálogo, reflexões e mudanças (CODO \& GAZZOTTI, 2000).

Segundo Rodrigues em sua Tese de Doutorado 2014, o termo afeto se origina do latim affectu que significa afetar, tocar. $\mathrm{O}$ afeto representa fenômenos psíquicos que se manifestam sob a forma de emoções, sentimentos e paixões, acompanhados sempre da impressão de prazer ou desprazer, de satisfação ou insatisfação, de agrado ou desagrado, de alegria ou tristeza.

Os trabalhos de Joseph Ledoux, neurocientista (1996/1998) indicam que as emoções pertencem a inúmeras classes. Elas são mediadas por sistemas neurais específicos que se desenvolveram mediante a resolução de problemas que os animais enfrentam na vida: "não existe a faculdade da emoção, e tampouco existe um sistema cerebral único encarregado dessa função fantasma" (p. 16). Antônio Damásio (2000, p. 88) afirma que: "não existe um único centro cerebral de processamento das emoções, e sim sistemas distintos relacionados a padrões emocionais separados".

A afetividade é a marca da motivação inerentemente humana, de desejar afetar e ser afetado pelo mundo externo e interno por meio de sensações vinculadas ao prazer e desprazer (ALMEIDA, 2009).

Desse modo, o afeto é uma sensação que se experiência no campo dos sentimentos. Eles, os afetos, se relacionam com as experiências reais, prazerosas e desprazerosas. La Taille (1992) diz que o afeto é fundante nas nossas ações, e a razão está ao seu comando. Os sentimentos e as emoções se diferenciam, mas se encontram interrelacionados. Eles advêm de estados subjetivos e integram a afetividade na concepção de Wallon (1995). Vale destacar que os sentimentos são mais profundos e duradouros do que as emoções. Elas surgem a partir das reações orgânicas e são sensações intensas. Observamos uma crescente preocupação dos estudiosos no campo da educação com essa temática haja vista o número limitado de produções, o que dificulta a consolidação de base teórica metodológica para as investigações. Isso faz com que o campo de estudos sobre a afetividade seja desafiador, mas exige cuidados no trato com essa abordagem (CODO, 2002, p. 51).

Do mesmo modo os estudos sobre papel das emoções na construção das representações sociais ainda é limitado. Banchs aponta que as representações sociais têm sofrido criticas pelo fato de não explicar o papel que a experiência privada e afetiva, quer dizer, a subjetividade individual, pode jogar na elaboração das representações (1995, p.97).

Esta dúvida ou lacuna quanto à explicação sobre o papel das emoções se amplia, por um lado, para a escola americana de psicologia social. Por outro, os teóricos que se intitulam construcionistas ao enfatizar acentuadamente a dimensão social, histórica, dinâmica e construtiva da realidade atribuem à emoção um papel cognitivo presente na narrativa de grupos sociais e, portanto atribuem a ela um caráter coletivo.

Desse modo, as emoções e afetos prazerosos e desprazerosos estão presentes e são elos fundamentais no processo de construção de representações sociais, pois o ato de representar só se torna necessário quando a ideia sobre algum objeto ou alguém se vincula ao afetivo-emocional. Implica em dizermos que a dimensão afetiva é parte ativa na representação.

Entendemos que a critica sobre o papel das emoções e do afeto nas representações sociais reside muito mais por ela ser pouco enfatizada nos estudos sobre as representações sociais do que propriamente a sua negação enquanto uma dimensão imprescindível na construção das representações sociais.

Se a representação é elaborada a partir da pactuação de um grupo social e resulta em uma elaboração mental que consolida um conhecimento que passa a assumir uma função determinante no modo como estes sujeitos se constituem e constroem a realidade, é evidente que as emoções e afetos estão presentes desde o início deste processo de construção.

\section{Metodologia}

Elegemos as referências da Teoria das Representações Sociais de Moscovici na perspectiva das objetivações e as ancoragens que constituem as representações sociais professores sobre o prazer e desprazer no trabalho que realizam. Além de nos utilizarmos de estudiosos do campo das emoções e do afeto para subsidiar a compreensão destas temáticas.

Cumpre destacar que se o vínculo afetivo se articula ao prazer e desprazer como aspectos envolvidos nas relações humanas. Esses dois moduladores foram utilizados nessa investigação para caracterizar o vínculo afetivo.

Os objetivos traçados foram:

a) Identificar e destacar aspectos centrais prazerosos e desprazerosos de professores sobre a profissão docente.

b) Ressaltar as objetivações e as ancoragens que constituem as RS de professores de séries iniciais sobre o prazer e desprazer no trabalho que realizam.

Os Sujeitos do estudo foram 35 professoras das series iniciais de escolas públicas. Essas professoras se encontram na faixa etária entre 25 a 49 anos. Todas elas contribuem ativamente com a renda familiar. Somente uma professora aguarda completar em dois anos o seu tempo de serviço para se aposentar. $O$ instrumento utilizado implicou na escrita individual de um texto sobre os prazeres e desprazeres da profissão docente e perspectivas. 
Para a análise qualitativa das informações, utilizamos o texto elaborado pelas professoras, agrupados em unidades de significados, seguido da classificação dessas unidades em temáticas e respectivas atribuições do que dá prazer e e/ou desprazer na profissão de professor. As temáticas abaixo referendam o que mencionamos:

a) Reconhecimento do vínculo

b) Reflexões sobre o trabalho que realizam

c) A distribuição do tempo/ trabalho

d) Aprendizado do Aluno/ Desinteresse das famílias

e) Desafios

f) Aspectos a serem superados na profissão

Cumpre observar que as falas das professoras foram referenciadas pela idade cronológica.

\section{a) Reconhecimento do vínculo:}

Vinte das professoras escolheram esta profissão por ser um sonho que alimentam desde a infância. As outras quinze fizeram suas escolhas estimuladas pelos familiares como a avó e a mãe que por sua vez transmitiu a crença de que na profissão de professora existe emprego garantido. Esse vínculo da escolha da profissão foi prazeroso para elas.

As falas abaixo ratificam o que mencionamos:

(...) Eu fui ser professora por que tenho esse sonho desde criança (professora, 24 anos e professora, 32 anos).

\section{(...) Eu escolhi ser professora por causa da minha avó (professora, 24 anos).}

Eu acabei sendo professora por causa da minha mãe, que dizia que eu sempre teria emprego de professora (professora, 35anos).

\section{b) Sobre o trabalho que realizam:}

Mesmo correndo contra o tempo, expressão utilizada por uma das professoras, todas elas avaliam as suas atuações como satisfatórias diante da ginástica que fazem todos os dias. Esse vínculo da escolha da profissão é prazeroso por um lado e por outro é desprazeroso por terem elegido uma profissão que exige muito do profissional.

As falas abaixo exemplificam esse pensamento: A ginástica que fazemos é grande para dar conta da aprendizagem dos nossos alunos. A gente sabe que a cobrança vai para nós (professora, 35 anos).

A aprovação do aluno no final do ano vem pra cima da gente. O pai não quer saber se ele mesmo não ajudou. Ele pressiona a escola que nos pressiona (professora, 45 anos).

O lugar que ocupamos embora valorizado por nós ele é desvalorizado na sociedade (professora, 35anos).

Tive prazer em escolher a minha profissão (professora, 40 anos).

\section{c) A distribuição do tempo/ trabalho:}

A distribuição do tempo no trabalho do professor segundo as professoras informantes é algo que causa desprazer. Existe pouco tempo para o planejamento de atividades, correção de trabalhos e provas, leitura, pesquisa, reuniões com a coordenação ou pais de alunos sem contar que o tempo que sobra para as atividades da vida privada é bastante restrito e na maioria das vezes ele é utilizado para complementar as atividades do professor.

Os finais de semana de acordo com suas informações elas se dividem entre o planejamento escolar e as atividades de casa. Vejamos a transcrição abaixo da fala de uma das professoras sobre o assunto mencionado:

A nossa vida é de dedicação com a escola, com os alunos o tempo que sobra para outras coisas da nossa vida ainda é dividido com os afazeres da escola como: preenchimento do diário de classe, correção de provas de trabalhos, planejamento semanal, avaliação... Tudo é cobrado, mas eu faço Esse vínculo da escolha da profissão é prazeroso para elas, pois gosto de ter tudo organizado. (professora, 28 anos)

O que sobra, (...) é muito pouco tempo para o lazer, cultura e de vida pessoal (professora, 32 anos).

d) Aprendizado do Aluno/ Desinteresse das famílias:

A percepção de que o aluno está se desenvolvendo na aprendizagem, segundo elas é muito prazeroso além de gostar de ensiná-las. De acordo com as falas abaixo:

Gosto de ver o meu aluno aprendendo. Isso me dá muito prazer (professora 45 anos) Todas nós gostamos de trabalhar com crianças (professora, 30 anos).

O desprazer na fala dessas professoras é gerado pelas famílias dos alunos que não contribuem com a educação de seus filhos e nem sabem educa-los. Esses pais, segundo elas, não assumem responsabilidades pelos filhos, transmitindo-lhes valores e dando-lhes limites.

As falas abaixo de algumas professoras exemplificam o que mencionamos:

As famílias destes alunos não contribuem com elas em relação à educação de boas maneiras, bons sentimentos quanto à fixação da aprendizagem na escola (professora, 42 anos).

Os pais em sua maioria são distantes e pouco ajudam seus filhos. Às vezes prejudicam e causam mais problemas do que os alunos. Eles, hoje em dia, se responsabilizam menos pelos filhos. Eles não sabem educar seus filhos por que os deixam fazer o que querem (professora, 37 anos).

A fala de duas professoras s exemplificam as ideias que elas partilham sobre a família:

(...) na maioria das vezes a mãe e o pai acha que a escola é que deve educar e eles não assumem a 
educação do filho. Eles fazem o que querem e não acontece nada. (professora, 32 anos)

(...) Se fossemos esperar pela família deles eles não seriam nada. Tá difícil hoje os pais saberem educar. (professora, 45 anos)

\section{e) Desafios:}

O professor, no pensamento dos trinta e cinco professoras alvo do estudo, possui um duplo desafio nos dias de hoje: o da atualização sobre novas metodologias que facilitem o ensino e a aprendizagem e contemplem o trabalho com as diferenças e a formação para lidar com questões que envolvem a formação do aluno.

O tempo de cada uma já se encontra sobrecarregado de atividades, segundo elas e isto dificulta até mesmo uma reivindicação neste sentido causando-lhes desprazer.

Vejamos abaixo trechos da escrita de duas professoras:

A gente tem desafios em dose dupla na escola de hoje. Um é com a nossa atualização, com o conhecimento de metodologias para o ensino e a aprendizagem e que possamos trabalhar sem esquecer as diferenças (professoras, 39 anos e 42 anos).

Precisamos saber lidar com as questões da formação do aluno, por exemplo: a violência, as drogas e outros problemas que interferem na aprendizagem e na formação do aluno. Mas o tempo que temos já está todo tomado e não temos nem como fazer tudo isso para avançar (...) (professoras, 32 anos e 35 anos).

\section{f) Aspectos a serem superados na profissão:}

Elas destacam aspectos a serem superados, mas não sabem por onde começar. Um deles é o fator tempo, que funciona como desmotivador para que essas trinta e cinco professoras vençam os desafios que o contexto histórico social impõe ao trabalho do professor. A desvalorização e a falta de reconhecimentos, somados aos baixos salários praticados para a profissão, representam para as professoras ouvidas não somente o que elas vivem nos dias atuais, mas também uma ameaça à saúde, a motivação, a dedicação e o compromisso com que desenvolvem suas atividades na escola.

Por entre a desvalorização do trabalho do professor e as demandas que se constroem na sociedade contemporânea sobre ele, não é tarefa fácil compreender a complexidade que se enlaça na constituição deste profissional e de seu trabalho.

Estas trinta e cinco professoras do ensino fundamental de duas escolas municipais, uma localizada no centro e a outra na periferia da cidade de Belém, expressam em suas falas as suas representações sobre lugar de professora, as suas motivações e as desmotivações bem como os prazeres e desprazeres, os requisitos para ser um professor nos dias atuais, as influências que tiveram na escolha da profissão, o tempo que dedicam para planejar as suas atividades de professor e a avaliação que fazem sobre a realização de seus trabalhos de professora, sobre a escola e sobre o ensino.

Por fim, elas falam dos desafios que a profissão e o trabalho do professor vivem nos dias atuais decorrentes das demandas do contexto histórico social contemporâneo, no qual o processo ensinoaprendizagem, tanto do professor quanto do aluno, requer transformações não somente pelas inovações tecnológicas, mas também pelo acelerado número de informações e transformações nas relações e modos de vida. As entrevistadas emitem sugestões para superar estes desafios, sem, contudo, visualizarem formas de realização em função da indisponibilidade de tempo para as atividades que possibilitarão as suas atualizações.

\section{As Representações Sociais de Professores de séries iniciais sobre o envolvimento da afetividade na sua profissão}

As tendências de objetivações e ancoragens que compõem as representações sociais das professoras do ensino fundamental das series iniciais sobre $o$ envolvimento da afetividade na sua profissão encontram seus sentidos centralizados entre o prazer e o desprazer com a perspectiva muito maior para o desprazer. Significa que existe um vínculo afetivo prazeroso na opção que essas professoras fizeram pela profissão. Contudo, o trabalho dessas professoras embora ancore seus sentidos em um vinculo afetivo prazeroso por gostarem de crianças, de ensiná-las e vê-las aprendendo o que elas ensinam verificamos que existe um vínculo afetivo maior de desprazer pela desvalorização e a falta de reconhecimentos que recai sobre o trabalho do professor, somado aos baixos salários praticados para a profissão, além da precária estrutura pedagógica e física na qual desenvolvem suas atividades relativas ao trabalho que realizam. Em função do vínculo desprazeroso no trabalho que desenvolvem essas professoras se sentem ameaçadas nos seguintes aspectos: na saúde, na motivação, na dedicação e no compromisso com o qual desenvolvem suas atividades na escola.

A reflexão sobre estas questões que essas professoras, alvo do estudo fazem é parcial, uma vez que não fornece condições para que elas problematizem sobre a dinâmica de estabelecimento desses vínculos afetivos tanto os prazerosos quanto os deprazerosos na sua profissão. A parcialidade faz com que a proposição sobre as habilidades afetivas a serem desenvolvidas muito mais para o prazer estejam ausentes juntamente com as ações para a mudança de trama dos vínculos afetivos desprazerosos nas atividades que desenvolvem.

\section{Aproximações Conclusivas}

As informações que as professoras, alvo da pesquisa forneceram, nos remetem a uma trama de relações de poder e hegemonias determinadas pela história do trabalho do professor. As formas de pensar, de agir e de sentir que partilham com outros sujeitos da mesma profissão, sobretudo os do ensino fundamental, 
compõem as representações sociais que orientam as suas atividades profissionais. Cumpre observar que as tênues, e quase imperceptíveis, diferenças entre as professoras, ouvidas quanto às representações sociais que possuem sobre o prazer e desprazer no trabalho que fazem, circulam na esfera das contradições sendo que na contemporaneidade o desprazer com que essas professoras vivem em seu trabalho é maior.

Não resta dúvida que estas representações sobre o envolvimento da afetividade no trabalho que essas professoras possuem compõem uma cadeia de significantes que se vinculam ainda a cultura escolar responsável pelas negociações e pela hegemonia de idéias sobre o que é ser um bom professor em seu trabalho além de idealizar o que é uma boa escola.

Muito embora seja consenso entre as professoras que deve existir mudanças no trabalho que realizam elas ainda resistem em promovê-las por suas orientações se encontrarem impregnadas de ideias hegemônicas que transitam entre a sua reificação e o submetimento daquele (s) que integram tanto a profissão de professor quanto ao seu trabalho.

Consideramos que estas professoras se encontram imersas em uma rede de significados que as orienta no seu trabalho e respectivos vínculos afetivos de prazer e desprazer, sem, contudo, articularem mudanças necessárias e significativas para trabalharem com um prazer maior. Para além do trabalho que elas realizam a resposta aproximada sobre a pergunta: o que quer um professor com o seu trabalho ainda está por vir. Existem sentidos sobre o trabalho do professor a serem preenchidos permanentemente, por essas professoras do ensino fundamental, nas brechas dos dizeres da contemporaneidade. Isto não se trata somente de uma constatação no que se refere às professoras entrevistadas, mas podemos encarar como um desafio a todos os professores que atuam em outros níveis da educação no Brasil.

As representações sociais destas professoras sobre o envolvimento da afetividade no trabalho ancoram seus sentidos nas suas subjetividades ao mesmo tempo em que elas são construídas e recontextualizadas juntamente com o que realizam na profissão de professor.

\section{Referências}

ALMEIDA, A. R. S. A Emoção na Sala de Aula. Campinas: Papirus, 2009.

BANCHS, Maria. A. $O$ papel da Emoção na representação do SELF e do outro em membros de uma família incestuosa. Novas Veredas da Psicologia Social. São Paulo: Brasiliense: EDUC, 1995.

CODO, W. e GAZZOTTI. A. A. Trabalho $e$ afetividade. Educação: carinho $\mathrm{e}$ trabalho. $2^{\mathrm{a}} \mathrm{ed}$. Petrópolis: Vozes, 2000.

CODO, W. Educação: carinho e trabalho. $3^{\mathrm{a}}$ ed. Petrópolis: Vozes, 2002.

DAMÁSIO, A. O mistério da consciência (L. T. Mota, Trad.). São Paulo: Cia. das Letras, 2000.

FREITAS, M. E. A. Carne e os ossos do ofício acadêmico. Revista Organização \&
Sociedade, Salvador, v. 14, n. 42, p. 187-191, 2007. Disponível em: http://www.scielo.br/scielo.php\%3F/ script\%3Dsci_arttext\%26pid\%3DS1679-39512011000/ 400013

GOMES, C. A.; PEREIRA, M. M. A formação do professor em face da violência das/nas escolas. Cadernos de Pesquisa, Belo Horizonte, v. 39, n. 13, 2009. Disponível em: http://www.scielo.br/ scielo.php\%3Fpid\%3DS1413-

23112013000200010\%26script\%3Dsci_arttext

GOMES, R. Culturas de escola e identidades dos professores. Lisboa: Educa, 1993.

LA TAILlE, Y. de et al. Piaget, Vygotsky, Wallon: teorias psicogenéticas em discussão. São Paulo: Summus, 1992.

LEDOUX, J. O cérebro emocional. Os misteriosos alicerces da vida emocional (T. B. Santos, Trad.). Rio de Janeiro: Objetiva, 1998.

MANCEBO, D. Trabalho docente: subjetividade, sobre implicação e prazer. Psicologia: Reflexão \& Crítica, Porto Alegre, v. 20, n. 1, 2007. Disponível em: http://www.scielo.br/pdf/prc/v20n1/a10v20n1

MARTÍNEZ, D. I. V.; KOHEN J. Salud y trabajo docente: tramas do malestar en la escuela, Buenos Aires: Kapelusz, 1997.

OLIVEIRA, M. A. M.; FREITAS, M. V. T. Políticas contemporâneas para o ensino superior: precarização do trabalho docente? Revista ExtraClasse, Belo Horizonte, n.1, v. 2, 2008. Disponível em: http://www.scielo.br/scielo.php\%3Fpid\%3DS1413-

23112013000200010\%26script\%3Dsci_arttex

RODRIGUES, S. Eli. A dimensāo afetiva nas representações sociais de docentes da pós-graduação em educação. Tese. Programa de Pós-graduação em Educação Doutorado em Educação em Belém/Pa, 2014. Disponível em: http://repositorio.ufpa.br/jspui// bitstream/2011/6276/1/Tese_DimensaoAfetivaRepresen tacoes.pdf

WALLON, Henri. (1995). A evolução psicológica da criança. Lisboa, Edições 70. 